\section{$16^{\circ}$ \\ ERGODESIGN \\ USIHC CINAHPA}

$16^{\circ}$ Ergodesign - Congresso Internacional de Ergonomia e Usabilidade de Interfaces Humano Tecnológica: Produto, Informações Ambientes Construídos e Transporte

$16^{\circ}$ USIHC - Congresso Internacional de Ergonomia e Usabilidade de Interfaces Humano Computador

CINAHPA | 2017 - Congresso Internacional de Ambientes Hipermídia para Aprendizagem.

\title{
REDESIGN DE ABRIDOR DE LATAS E GARRAFAS SOB O VIÉS ERGONÔMICO.
}

\section{AN ERGONOMIC APPROACH TO REDESIGN A TIN AND BOTTLE OPENER}

\author{
Mirela Riquena De Giuli ${ }^{1}$ \\ Erica Tiemi Tobaro ${ }^{2}$ \\ Marina Soares Tomiatti ${ }^{3}$ \\ Emilene Zitkus ${ }^{4}, \mathrm{Dr}^{\mathrm{a}}$ \\ (1) Universidade Estadual Paulista - UNESP - Bauru \\ e-mail: mirela_rgiuli@outlook.com \\ (2) Universidade Estadual Paulista - UNESP - Bauru \\ e-mail: erica.tobaro@gmail.com \\ (3) Universidade Estadual Paulista - UNESP - Bauru \\ e-mail: marina.tomiatti@gmail.com \\ (4) Universidade Estadual Paulista - UNESP - Bauru \\ e-mail: emilenezitkus@gmail.com \\ Palavras-chave: Ergonomia, Usabilidade, Design
}

Utensílio indispensável em qualquer cozinha, o abridor de latas e garrafas é encontrado com facilidade em mercados ou lojas de utilidades domésticas. No entanto, os modelos mais comuns de abridores não costumam variar de formato e nem de material, o que os torna pouco atraentes e desconfortáveis durante a experiência de uso. Sendo assim, o presente artigo apresenta o resultado do trabalho interdisciplinar proposto pelos docentes do curso de Design de produto da UNESP, que teve como objetivo redesenhar e produzir um protótipo de abridor de latas e garrafas, colocando em prática os conhecimentos adquiridos durante as disciplinas de ergonomia, modelos e protótipos, desenho técnico e metodologia de projeto. $\mathrm{O}$ foco deste artigo está na metodologia utilizada para o desenvolvimento do projeto e produção, que enfatizou as características ergonômicas do produto, e a avaliação da experiência de uso através de testes e questionários de usabilidade.

Keywords: Ergonomics, Usability, Product design

Realização:
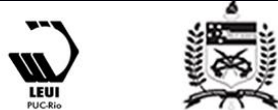
$16^{\circ}$ USIHC - Congresso Internacional de Ergonomia e Usabilidade de Interfaces Humano Computador

CINAHPA | 2017 - Congresso Internacional de Ambientes Hipermídia para Aprendizagem.

\begin{abstract}
One of the indispensable kitchen utensils, tin openers have been for years now, an object of design. However, those commonly displayed in Brazilian supermarkets do not vary greatly in their shape and material. Thus, they are not very attractive or considerably differ in the way of use. In this way, this paper presents a new approach taken by design students to redesign a 'tin and botle' opener. The project was developed as part of an interdisciplinary program of the product design school at Unesp, which encompassed four modules: ergonomics; models and prototypes; design methodology, and; engineering drawing(drafting). An ergonomic approach was taken in this project which emphasised usability aspects and tested a range of tin openers with young users as part of the project development process. The paper presents and discuss the results of such approach, highlighting the benefits of user tests.
\end{abstract}

\section{Introdução}

Apesar de ser um utensílio indispensável em qualquer cozinha, os modelos mais populares de abridores de latas e garrafas não costumam variar de formato e material, sendo geralmente pequenos, finos, com a lâmina de perfuração curva, pouco elaborados e feitos em metal. A pouca oferta de modelos diferentes coloca o usuário em condição desfavorável ao seu uso, fazendo com que este "aceite" o design do produto mesmo que este não lhe proporcione uma boa experiência de uso. No entanto, projetar ou aprimorar um dispositivo como o abridor de latas não é uma tarefa simples, e requer cuidado e atenção do designer. Isto se deve a uma série de fatores que devem ser levados em consideração durante todo processo de projeto do produto como, por exemplo, aspectos

ergonômicos, funcionais e estéticos que visem atender efetivamente as necessidades do usuário. Além dos atributos físicos, outro importante ponto a ser levado em consideração é o modelo mental que o usuário tem do produto, ou seja, o modelo que o usuário desenvolve para explicar a operação do sistema [NORMAN, 2006].

Esta relação entre o usuário e o sistema é um dos focos de pesquisa e aplicação de um projeto de produto, sendo que um de seus principais segmentos é o design ergonômico, cujo princípio é a aplicação do conhecimento ergonômico no projeto de dispositivos tecnológicos, com o objetivo de alcançar produtos e sistemas seguros, confortáveis, eficientes, efetivos e aceitáveis. [PASCHOARELLI, 2003]. E além do design ergonômico, a Usabilidade apresenta-se como um novo parâmetro para a compreensão dessa relação entre o usuário e sistema [PASCHOARELLI e CAMPOS, 2013].

Ao compreender a importância da interação do usuário com o produto, o designer deve buscar métodos para coletar as informações necessárias para nortear o projeto e dessa forma, incorporar ao produto as reais necessidades e desejos dos consumidores. Uma possibilidade é através da Ergonomia Participativa, descrito por Itiro Iida (2005) como o método pelo qual os usuários finais do produto desempenham um papel ativo na identificação e na análise dos problemas ergonômicos, assim como na formulação e implementação de suas soluções. No caso do redesenho do abridor de latas, que é um produto já existente, o desenvolvimento aconteceria através do Projeto Participativo, no qual o usuário é envolvido desde a etapa inicial. Desde o início o projeto é focalizado no usuário e na tarefa. Dessa forma, os usuários fazem avaliações contínuas a cada etapa do projeto. Assim, os eventuais erros ou desvios do projeto são corrigidos antes de se chegar ao protótipo. [IIDA, 2005]

O presente artigo apresenta o resultado do trabalho interdisciplinar proposto pelos docentes do curso de Design de produto da UNESP, que teve como objetivo redesenhar e produzir um protótipo de abridor de latas e garrafas, e desta forma colocar em prática os conhecimentos adquiridos durante as disciplinas de Ergonomia aplicada ao design II, Metodologia de Projeto, Modelos e Protótipos e Desenho Técnico IV. Os alunos foram divididos em equipes e, ao final, deveriam apresentar resultados que atendessem aos requisitos de cada uma das disciplinas. Ao final, o trabalho interdisciplinar resultou em um painel para apresentação do processo de desenvolvimento do 


\section{$16^{\circ}$ \\ ERGODESIGN USIHC CINAHPA}

$16^{\circ}$ Ergodesign - Congresso Internacional de Ergonomia e Usabilidade de Interfaces Humano Tecnológica: Produto, Informações Ambientes Construídos e Transporte

$16^{\circ}$ USIHC - Congresso Internacional de Ergonomia e Usabilidade de Interfaces Humano Computador

CINAHPA | 2017 - Congresso Internacional de Ambientes Hipermídia para Aprendizagem. protótipo e, principalmente, dos testes de usabilidade e suas respectivas análises; relatórios sobre os procedimentos metodológicos e produtivos, modelagens virtuais e renders; projeto executivo do produto e; um protótipo físico.

\section{Procedimentos metodológicos}

Os procedimentos metodológicos realizados no decorrer do desenvolvimento do protótipo se dividiram em: aplicação de testes de ergonomia e usabilidade com um abridor comum; pesquisa de similares; diretrizes iniciais de projeto; desenvolvimento de projeto e; produção do protótipo.

\subsection{Aplicação de testes de ergonomia e usabilidade com abridor comum}

Durante a disciplina "Ergonomia aplicada ao design II”, os docentes organizaram a aplicação de testes que tiveram como usuários os próprios alunos. Inicialmente a proposta era testar a abertura tanto de latas quanto de garrafas, porém, por motivos de segurança no ambiente universitário optou-se por não realizar os testes com as garrafas, mas apesar disso, manter esta função no projeto do produto. Deste modo, a atividade foi dividida em duas etapas: primeiramente os alunos tiveram que realizar a abertura de uma lata de ervilha fazendo uso de modelos de abridores de latas encontrados no mercado, e em seguida, responder a dois questionários referentes à experiência quanto à ergonomia, usabilidade e estética do abridor. Os testes foram feitos com duas metodologias diferentes, sendo que a primeira se baseava em uma lista com dez assertivas acerca da experiência de uso que o usuário deveria marcar se concordava totalmente, concordava parcialmente, não concordava nem discordava, discordava parcialmente e discordava totalmente com essas afirmações. Este tipo de teste é chamado de SUS (System Usability Scale), e cada posição de concordância ou discordância valia uma pontuação de 1 a 5 , sendo 1 o "discordo totalmente" e o 5 o "concordo totalmente". O cálculo da pontuação também muda de acordo com o tipo de pergunta, se for uma afirmação positiva sobre o produto, o cálculo deve ser feito com a fórmula "posição-1", logo, se o usuário concordar totalmente com a assertiva (posição que vale 5), então essa resposta dará 4 pontos ao produto, que é o máximo que uma questão positiva pode valer. Se a assertiva for negativa, a fórmula se altera para "5 - posição", então, se o usuário discordar totalmente da afirmação (posição que vale 1), essa resposta também dará 4 pontos ao produto.

Por exemplo, se o produto testado for excelente e o usuário concordar com todas as afirmativas positivas e discordar de todas as afirmativas negativas, a soma dos resultados dará 40. Mas para obter a pontuação geral do SUS, esse valor deve ser multiplicado por 2,5 . No exemplo dado, a pontuação geral seria 40*2,5 = 100 .

O segundo teste foi o DS (Diferencial Semântico). Nele, são colocados dez pares de adjetivos antagônicos, e o usuário deve indicar, numa escala de dez pontos, a qual dos adjetivos aquele produto mais se aproxima. A pontuação corre de 1 a 10 , e o resultado final é a soma de todas as médias de todos os pares de adjetivos. Cada um dos adjetivos recebe uma classificação entre positivo e negativo, e elas devem ser escolhidas antes da aplicação do teste. Para ilustrar, neste teste o par caro/barato, tem como elemento positivo o "barato" e negativo o "caro", e o objetivo do teste é que o produto seja percebido com mais características positivas possíveis, pois assim sua pontuação final irá aumentar.

Por exemplo, se um dos pares de adjetivos é "higiênico - anti-higiênico", sendo que o caráter positivo é o de higiênico, e o negativo é o de antihigiênico, e a percepção do usuário é de que aquele produto é muito higiênico, então a pontuação para esse par será com números altos. Ao final de todos os sujeitos testarem, é feita uma média com os valores atribuídos a cada par. E, ao final, todas as médias para os dez pares são somadas para chegar ao número final.

Como pode ser visto na Figura 1, os testes aplicados ao abridor comum tiveram médias de 63 pontos (SUS) e 49,70 pontos (DS). Essas médias colocam esse abridor em uma posição mediana de 


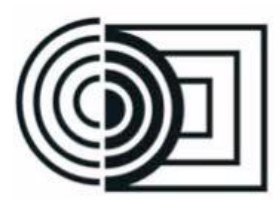
CINAHPA $16^{\circ}$ Ergodesign - Congresso Internacional de Ergonomia e Usabilidade de Interfaces Humano Tecnológica: Produto, Informações Ambientes Construídos e Transporte

$16^{\circ}$ USIHC - Congresso Internacional de Ergonomia e Usabilidade de Interfaces Humano Computador

CINAHPA | 2017 - Congresso Internacional de Ambientes Hipermídia para Aprendizagem. desempenho, não sendo excelente nem totalmente ruim. Pelo teste SUS, baseado nas perguntas, esse abridor teve pior desempenho nas questões que envolviam a facilidade da pega e a qualidade do material utilizado no produto. $\mathrm{O}$ resultado do teste DS mostrou que o abridor foi percebido pelos usuários como anti-higiênico, geométrico, barato, intuitivo, repulsivo, sério, anti-ergonômico, minimalista, poluente, excludente, rústico e indesejável.

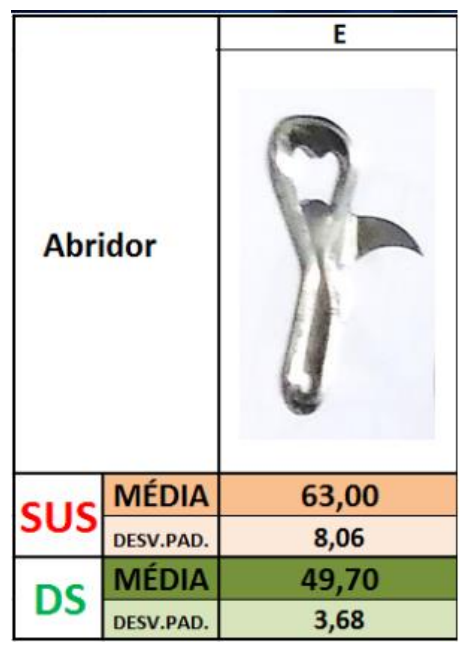

Figura 1 - Resultados dos testes aplicados ao abridor comum. Fonte: Medola e Paschoarelli, 2016.

\subsection{Pesquisa de similares}

A etapa de pesquisa de similares teve como objetivo conhecer melhor os modelos de abridores disponíveis no mercado para, assim, ser possível listar suas principais características, como tamanho, formato, material e preços de comercialização. A equipe buscou imagens que fugissem do formato convencional de um abridor de latas e de garrafas, mas é difícil encontrar produtos que sejam muito diferentes do modelo que foi usado nos testes de usabilidade aplicados em sala de aula. De qualquer modo, de cada abridor encontrado foi possível extrair características que pudessem auxiliar a criação de algo novo, ergonômico e com melhorias estéticas. Alguns desses itens podem ser vistos nas figuras 2 e 3 .

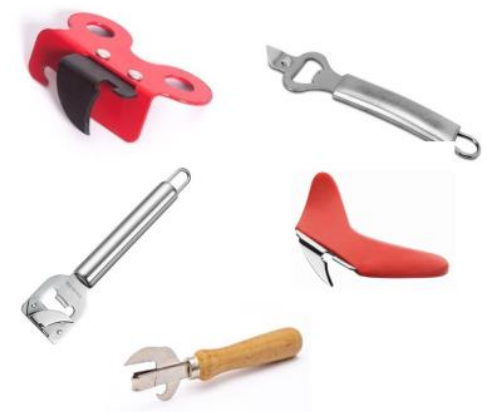

Figura 2 - Similares do abridor de latas. Fonte: Elaborado pelas autoras, 2017.

Esses abridores são modelos diferentes dos abridores comuns, principalmente pelas pegas em forma de cabo, e pelos materiais utilizados, que são de madeira ou borracha, ou até mesmo de metal colorido.

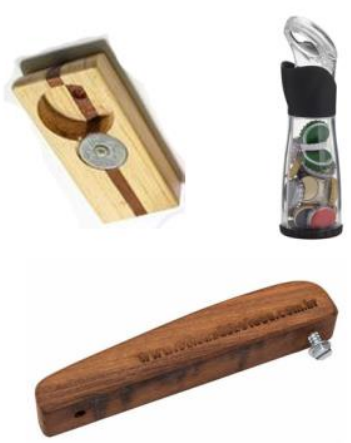

Figura 3 - Similares do abridor de garrafas. Fonte: Elaborado pelas autoras, 2017.

O abridor de garrafas, embora não tenha sido testado, foi uma parte importante do desenvolvimento do protótipo, uma vez que ele seria útil para equilibrar o formato do produto. Assim, foi feita a busca por modelos que fossem muito diferentes dos tradicionais. Através dessa pesquisa, viu-se a necessidade de criar um meio de segurar a tampa da garrafa, de modo a evitar que esta caísse quando fosse aberta.

\subsection{Diretrizes iniciais de projeto}




\section{$16^{\circ}$ \\ ERGODESIGN USIHC CINAHPA}

$16^{\circ}$ Ergodesign - Congresso Internacional de Ergonomia e Usabilidade de Interfaces Humano Tecnológica: Produto, Informações Ambientes Construídos e Transporte

$16^{\circ}$ USIHC - Congresso Internacional de Ergonomia e Usabilidade de Interfaces Humano Computador

CINAHPA | 2017 - Congresso Internacional de Ambientes Hipermídia para Aprendizagem.
As conversas iniciais para o desenvolvimento do projeto foram pautadas na experiência pessoal que cada membro da equipe teve com o produto, em conversas com usuários que trabalhavam em bares e restaurantes, e nos resultados dos testes DS e SUS que foram feitos com o abridor de latas comum.

Sendo assim, ficou claro que o tipo de pega e a área de contato entre a mão do usuário e o corpo do produto precisavam ser alterados para melhorar a experiência de uso, de modo a facilitar o movimento que se faz ao abrir a lata e preservar os músculos da mão. Além disso, uma das diretrizes iniciais era fazer um produto que fosse tanto para destros quanto para canhotos, mas não foi possível atingir esse objetivo pela dificuldade em manipular o metal da lamina.

O resultado do teste de usabilidade permitiu perceber com clareza melhoras pontuais a serem aplicadas ao abridor comum, e, assim, as diretrizes de projeto selecionadas foram:

- $\quad$ Conforto ao usuário;

- $\quad$ Produto com maior área de contato com a mão do usuário;

- $\quad$ Alteração da pega para diminuir o stress muscular;

- Modificação do sistema de abertura de garrafas;

- Utilização da madeira para a construção do corpo do produto.

\subsection{Desenvolvimento de projeto}

A equipe fez muitos sketches que tentaram conciliar a melhora ergonômica com a melhora estética e funcional, mas a maioria das soluções apresentavam falhas graves em um ou mais quesitos e, por isso, foram logo descartadas. Após alguns estudos com sketches (Figura 4), a equipe achou que seria mais interessante elaborar a modelos físicos para que algumas das soluções fossem testadas antes de serem aplicadas no protótipo final, assim, haveria chance de alterar o projeto sem que os resultados prejudicassem o desempenho do produto durante os testes.

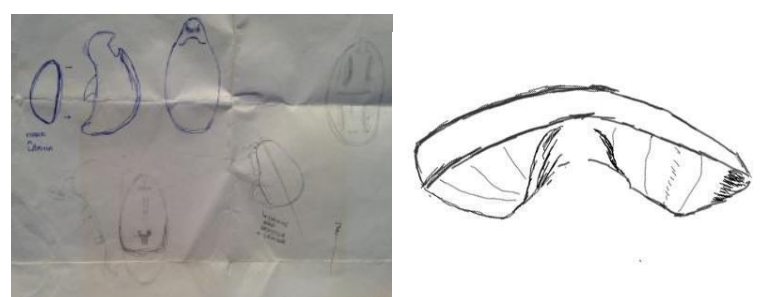

Figura 4 - Sketches. Fonte: Elaborado pelas autoras, 2017.

Os modelos foram feitos em madeira de eucalipto, PU (poliuretano expandido) e massa de modelar como mostra a figura 5 e, quando possível, foi feito um teste para avaliar o desempenho do abridor de latas com os modelos de corpo. Desses testes a equipe extraiu que nem tudo traria melhoria, e essas ideias foram descartadas e deram lugar para outras mais adequadas.

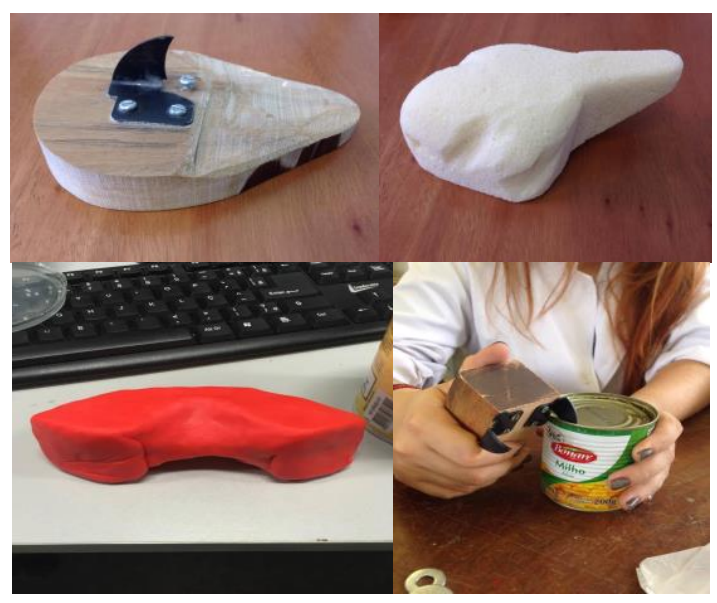

Figura 5 - Estudos para geração de alternativas. Fonte: Elaborado pelas autoras, 2017.

Apesar dos resultados esclarecedores, a equipe ainda não havia definido o formato final do produto, pois houve certa dificuldade em encontrar um desenho que unisse a ergonomia, a funcionalidade e a beleza. Mas, foi apenas durante uma discussão sobre a memória que cada uma tinha sobre produtos de pega confortável, que surgiu a ideia de usar o cabo da plaina manual como inspiração para o design (figura 6). 


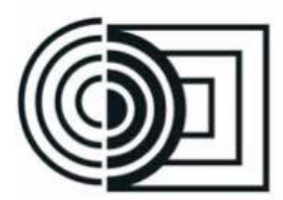
CINAHPA

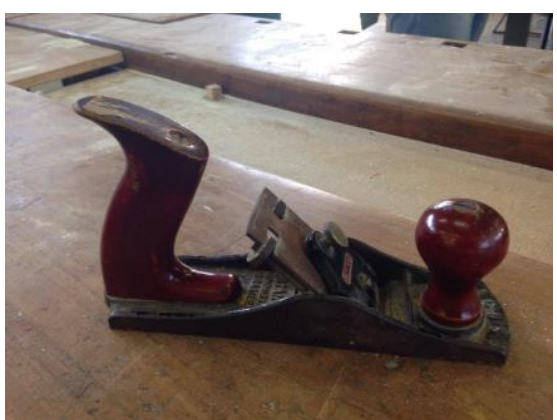

Figura 6 - Referência para o formato do abridor. Fonte: Fotografado pelas autoras, 2017.

A plaina foi usada por dois membros da equipe durante o desenvolvimento de outro projeto, e o conforto e segurança que esse cabo ofereceu durante o uso da ferramenta foi notável, e essa experiência de uso era o que buscávamos para o produto, então concordamos em investir nessas curvas paralelas que culminam em planos quase equivalentes.

O material selecionado para o corpo do novo abridor foi a madeira de eucalipto por sua fácil obtenção, resistência, possibilidade de ser modelada com os equipamentos disponíveis na Universidade, conferir um bom acabamento ao produto e também pelo fato da madeira ser um material já introduzido na composição de utensílios de cozinha, o que facilita sua introdução no mercado.

Feitas as definições quanto a forma e material, partimos para a etapa de modelagem virtual, que teria como objetivo não só nos permitir visualizar como seria o formato final do abridor, mas também gerar seu projeto executivo.

A modelagem virtual foi feita com o auxilio do software SolidWorks e SolidEdge, e a renderização foi feita no Keyshot. Como resultados foram gerados renders e as pranchas do projeto executivo, apresentados a seguir nas figuras de 7 a 9. $16^{\circ}$ Ergodesign - Congresso Internacional de Ergonomia e Usabilidade de Interfaces Humano Tecnológica: Produto, Informações Ambientes Construídos e Transporte

$16^{\circ}$ USIHC - Congresso Internacional de Ergonomia e Usabilidade de Interfaces Humano Computador

CINAHPA | 2017 - Congresso Internacional de Ambientes Hipermídia para Aprendizagem.

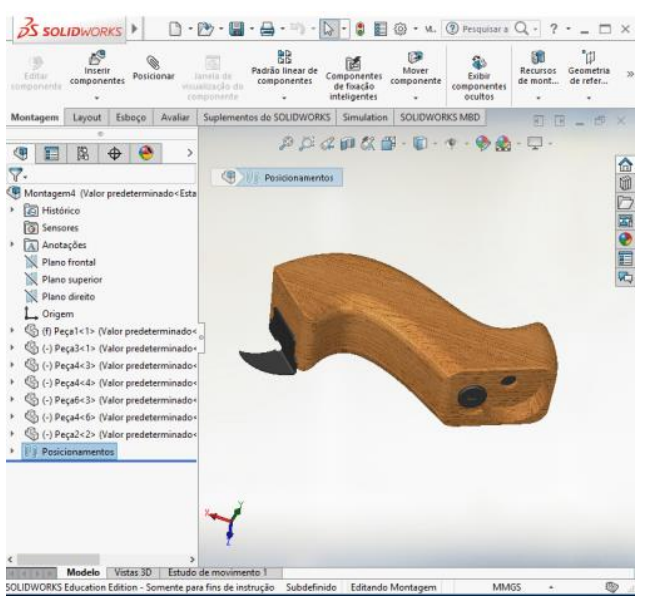

Figura 7- Montagem do abridor com todos os componentes posicionados

Fonte: Imagem gerada pelas autoras, 2017.

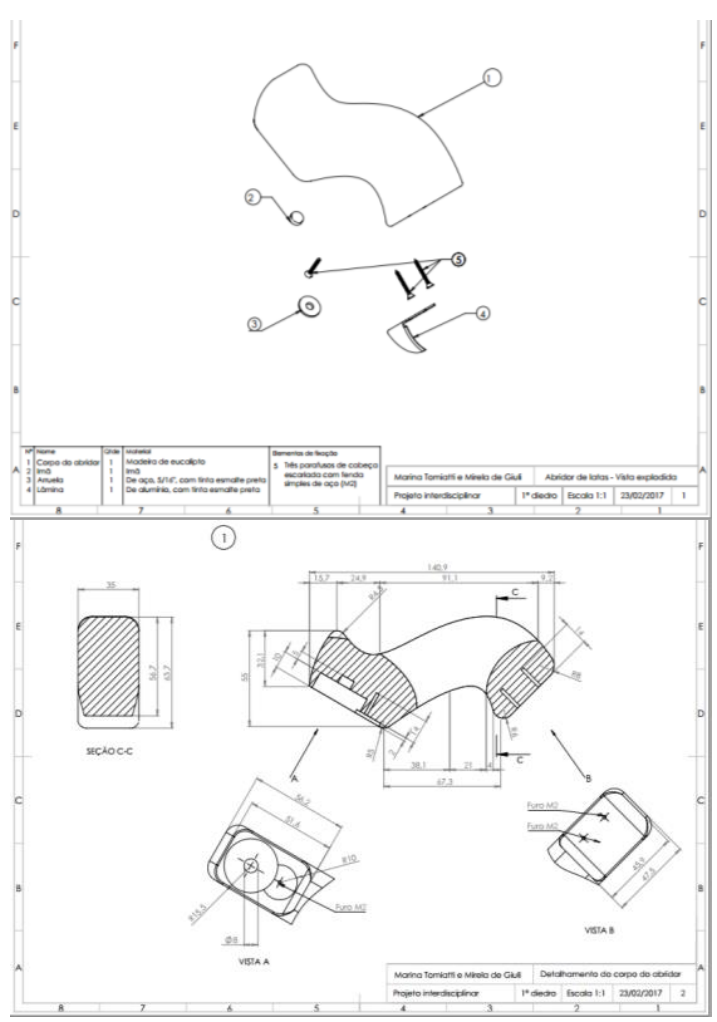

Figura 8-Desenho técnico/ vista explodida e detalhamento do corpo do abridor.

Fonte: Imagem gerada pelas autoras, 2017. 


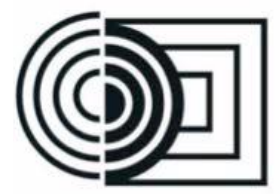
CINAHPA

$16^{\circ}$ Ergodesign - Congresso Internacional de Ergonomia e Usabilidade de Interfaces Humano Tecnológica: Produto, Informações Ambientes Construídos e Transporte

$16^{\circ}$ USIHC - Congresso Internacional de Ergonomia e Usabilidade de Interfaces Humano Computador

CINAHPA | 2017 - Congresso Internacional de Ambientes Hipermídia para Aprendizagem.

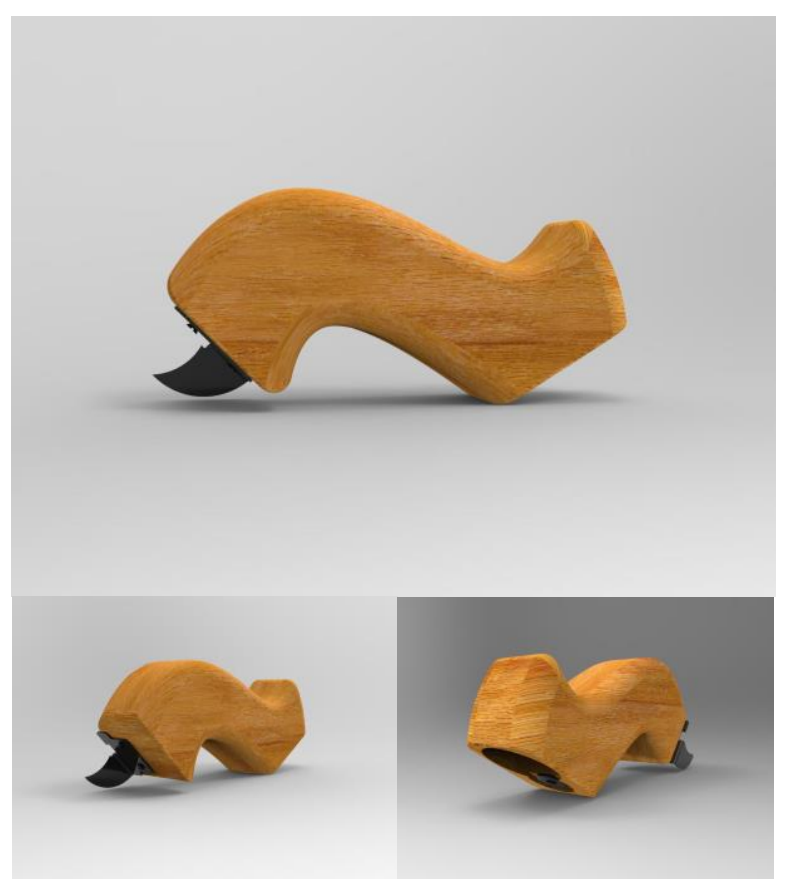

Figura 9 - Renders Fonte: Imagem gerada pelas autoras, 2017.

\subsection{Produção do protótipo}

A produção do protótipo foi realizada no Laboratório Didático de Materiais e Protótipos (LDMP) da UNESP, com processos manuais e técnicas básicas de marcenaria. Foi necessário colar pedaços de madeira para formar um bloco, como mostra a Figura 10, e a partir desse bloco retangular foi feita a retirada de material até que a forma final fosse atingida.

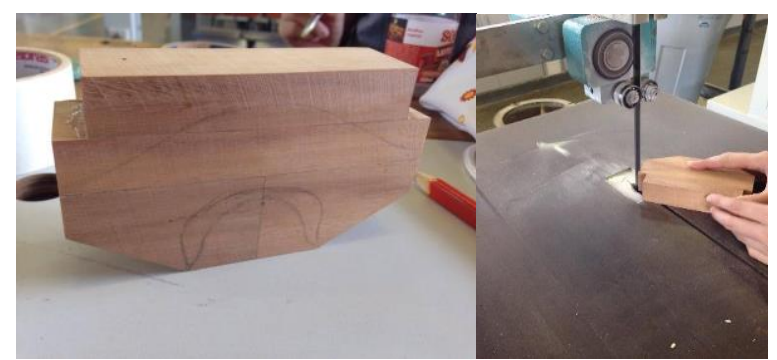

Figura 10 - Formação do bloco e primeiros cortes. Fonte: Imagem gerada pelas autoras, 2017.

O corte das quinas da peça foi feito com a serra de fita (Figura 11), mas a maior parte do desbaste foi feito com lixas, tanto com equipamento elétrico (lixadeira circular), quanto os manuais (retífica, grosa e folha de lixa) mostrados nas figuras $12 \mathrm{e}$ 13.

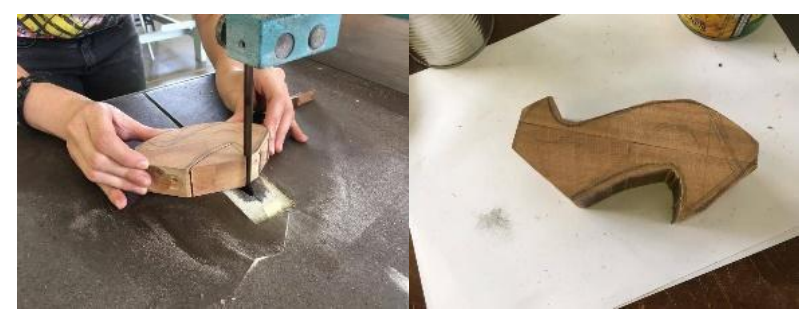

Figura 11 - Corte das quinas no serra de fita. Fonte: Imagem gerada pelas autoras, 2017.

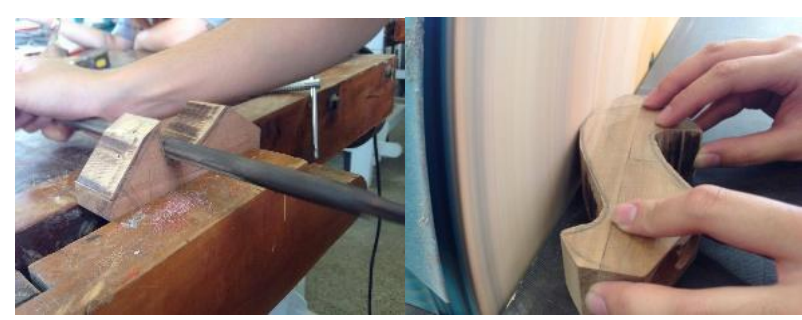

Figura 12 - Desbaste da peça com grosa e lixadeira. Fonte: Imagem gerada pelas autoras, 2017.

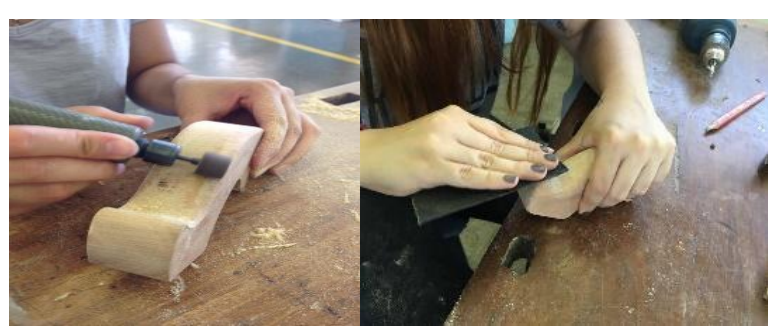

Figura 13 - Desbaste e arredondamento dos cantos da peça com retifica e lixa. Fonte: Imagem gerada pelas autoras, 2017.

O acabamento foi feito com aplicação de uma camada de verniz (Figura 14) e a lâmina foi retirada de um abridor convencional, e apenas recebeu uma camada extra de tinta preta, assim como os outros componentes de fixação e o componente para o abridor de garrafas (arruela). 


\section{$16^{\circ}$ \\ ERGODESIGN USIHC CINAHPA}

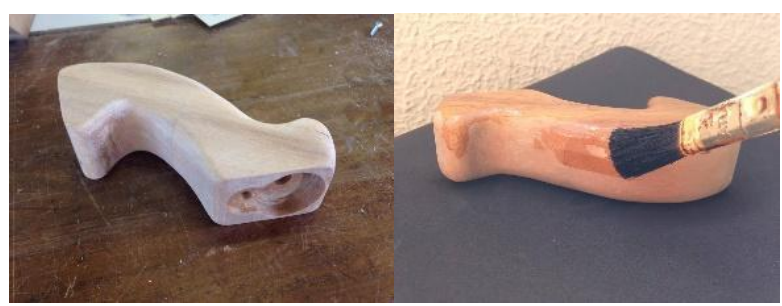

Figura 14 - Acabamento com aplicação de verniz. Fonte: Imagem gerada pelas autoras, 2017.

Abaixo, na figura 15, fotos do protótipo final do abridor.

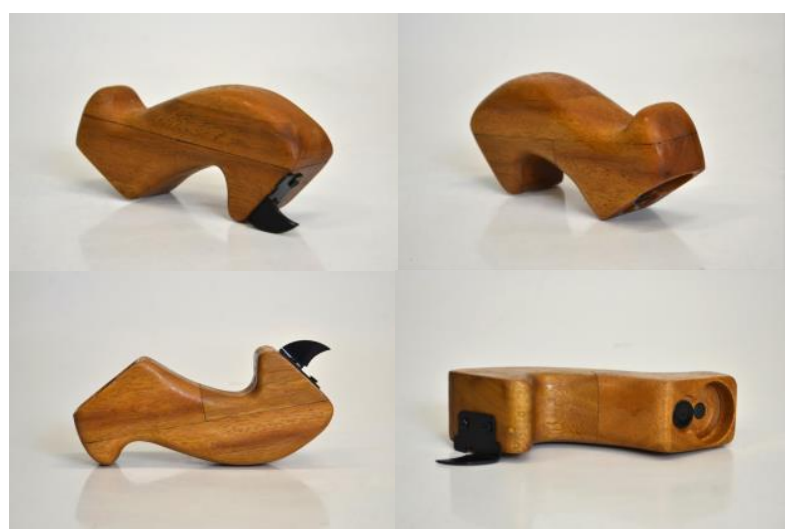

Figura 15 - Protótipo final do abridor. Fonte: Imagem gerada pelas autoras, 2017.

\section{Resultados e Discussões}

Com o protótipo físico acabado, foi realizada a aplicação dos testes de ergonomia e usabilidade para o novo modelo a fim de recolher dados numéricos para serem comparados ao modelo de abridor comum previamente testado, e, assim, observar o resultado do redesenho do produto.

\subsection{Aplicação de testes de ergonomia e usabilidade com o protótipo}

A aplicação dos testes de ergonomia e usabilidade com o protótipo também foram realizadas em sala de aula com o acompanhamento dos docentes tendo como usuários os alunos membros das outras $16^{\circ}$ Ergodesign - Congresso Internacional de Ergonomia e Usabilidade de Interfaces Humano Tecnológica: Produto, Informações Ambientes Construídos e Transporte

$16^{\circ}$ USIHC - Congresso Internacional de Ergonomia e Usabilidade de Interfaces Humano Computador

CINAHPA | 2017 - Congresso Internacional de Ambientes Hipermídia para Aprendizagem.

equipes (Figura 16). As equipes foram dispostas no ambiente da sala de aula de forma que em cada mesa houvesse um protótipo, a lata a ser aberta e pelo menos um membro da equipe que $o$ desenvolveu. Os docentes desenvolveram uma tabela que continha o um número de identificação para cada aluno, a ordem da rodada de teste e para qual mesa o aluno deveria se deslocar ao final de cada rodada. $\mathrm{O}$ objetivo era que dessa forma cada aluno testasse pelo menos três dos protótipos desenvolvidos pelas equipes e que cada protótipo avaliado por 9 alunos, sendo que os membros da equipe não testaram o próprio protótipo para o levantamento de dados dessa atividade. As etapas de teste foram divididas em: atividade de abertura de uma lata de milho com tempo cronometrado e o posterior preenchimento dos questionários SUS e DS (Figura17).

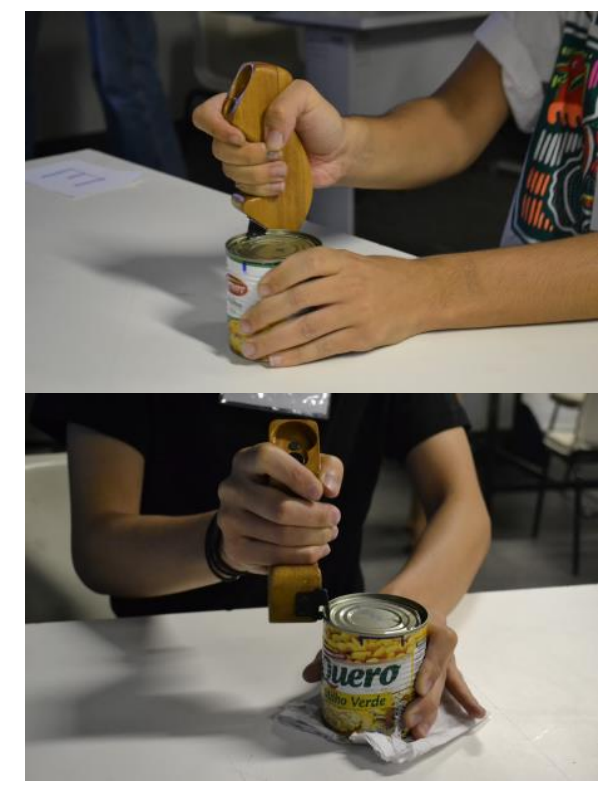

Figura 16 - Teste de usabilidade do protótipo. Fonte: Imagem gerada pelas autoras, 2017. 


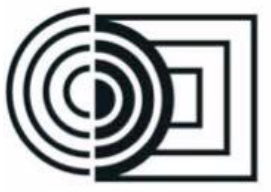

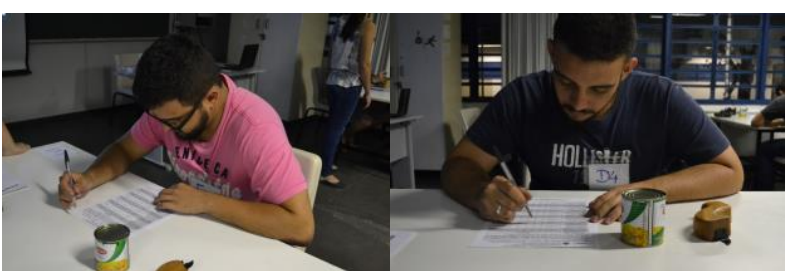

Figura 17 - Aplicação dos questionários SUS e DS. Fonte: Imagem gerada pelas autoras, 2017.

\subsection{Análise dos resultados}

A figura 18 traz os resultados dos testes de ergonomia e usabilidade aplicados ao protótipo, que foram exatamente iguais aos testes aplicados anteriormente. Desta forma, é possível comparar o desempenho dos dois produtos, assim como verificar quais pontos foram melhorados e quais foram piorados.

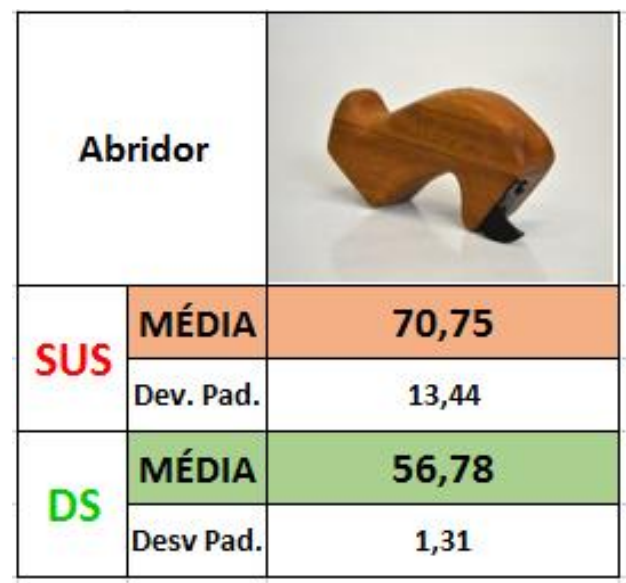

Figura 18 - Resultados dos testes aplicados ao protótipo.

Fonte: Elaborado pelas autoras, 2017.

De maneira geral, tanto o teste DS quanto o SUS tiveram resultados superiores aos do abridor comum. A melhora, em ambos os casos, foi de $11 \%$, o que é muito positivo para a avaliação geral do protótipo, porque, mesmo sendo o primeiro teste, foi possível melhorar o desempenho geral do produto frente aos usuários.

A análise do resultado do SUS mostra que das dez questões, seis obtiveram melhores pontuações $16^{\circ}$ Ergodesign - Congresso Internacional de Ergonomia e Usabilidade de Interfaces Humano Tecnológica: Produto, Informações Ambientes Construídos e Transporte

$16^{\circ}$ USIHC - Congresso Internacional de Ergonomia e Usabilidade de Interfaces Humano Computador

CINAHPA | 2017 - Congresso Internacional de Ambientes Hipermídia para Aprendizagem. quando comparadas ao teste com o abridor comum, como pode ser visto no gráfico 1, abaixo.

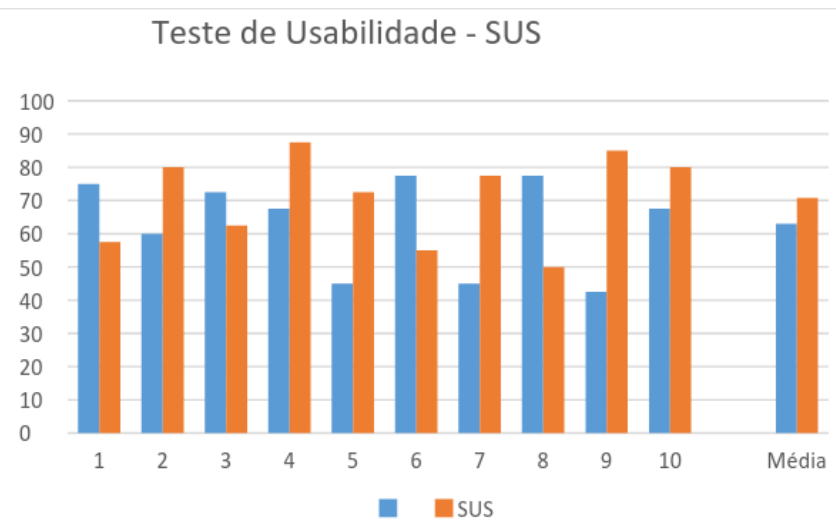

Gráfico 1- Teste de usabilidade SUS. Fonte: Elaborado pelas autoras, 2017.

Essas quatro questões, que eram a de número 1, 3, 6 e 8, tratavam sobre o design formal do produto, sua manipulação, seu formato e sua facilidade de uso. A equipe previa que esse aspecto não seria tão bem avaliado, visto que o corpo do abridor e sua pega foram completamente modificados e em nada se assemelha ao abridor comum. Assim, já era de se esperar que houvesse certa dificuldade ao entender o modo de uso do produto. Apesar disso, é fato que esse ponto precisa ser melhorado para que os usuários compreendam a forma de manipulação intuitivamente, e não tenham dúvidas quanto a maneira de utilizar o abridor.

O teste DS apresentou melhorias também. Dos doze pares, sete tiveram aumento na pontuação e alteração do adjetivo mais próximo da experiência de uso. Neste teste, o protótipo foi percebido como higiênico, anatômico, atraente, ergonômico, sustentável, elaborado e desejável. Todos esses adjetivos foram considerados positivos para esse teste, e se opuseram aos adjetivos escolhidos para o abridor comum, que eram todos negativos.

A figura 19 compara os resultados dos testes com os dois abridores, e demonstra que houve uma melhora significativa na percepção do objeto. Entretanto, dois adjetivos negativos se mantiveram nos dois produtos, que foram "sério" e 


\section{ERGODESIGN \\ ERGODESIGN USIHC CINAHPA}

"excludente". Outros três pares, que antes eram avaliados com características positivas, no protótipo foram avaliados com características negativas, que são "caro", "complicado" e "exagerado".

\begin{tabular}{|c|c|c|c|c|}
\hline \multicolumn{5}{|c|}{ DS } \\
\hline \multirow{2}{*}{$\begin{array}{r}\text { Negativo/Positivo } \\
\text { ANTI-HIGIÊNICO/HIGIÊNICO }\end{array}$} & \multicolumn{2}{|c|}{ Teste com abridor comum } & \multicolumn{2}{|c|}{ Teste com protótipo } \\
\hline & 4,8 & Anti-higiênico & 5,8 & Higiênico \\
\hline GEOMÉTRICO/ANATÔMICO & 4,0 & Geométrico & 5,2 & Anatômico \\
\hline CARO/BARATO & 6,5 & Barato & 2,6 & Caro \\
\hline COMPLICADO/INTUITIVO & 5,2 & Intuitivo & 4,1 & Complicado \\
\hline REPULSIVO/ATRAENTE & 3,9 & Repulsivo & 6,1 & Atraente \\
\hline SÉRIO/DIVERTIDO & 2,6 & Sério & 3,1 & Sério \\
\hline ANTI-ERGONÔMICO/ERGONÔMICO & 4,0 & Anti-ergonômico & 5,8 & Ergonômico \\
\hline EXAGERADO/MINIMALISTA & 5,2 & Minimalista & 3,4 & Exagerado \\
\hline POLUENTE/SUSTENTÁVEL & 3,8 & Poluente & 5,9 & Sustentável \\
\hline EXCLUDENTE/INCLUSIVO & 2,7 & Excludente & 3,6 & Excludente \\
\hline RÚSTICO/ELABORADO & 3,1 & Rústico & 5,0 & Elaborado \\
\hline INDESEJÁVEL/DESEJÁVEL & 3,9 & Indesejável & 6,2 & Desejável \\
\hline MÉDIA & & 49,70 & & 56,78 \\
\hline \multicolumn{5}{|l|}{$\begin{array}{l}\text { " Prevalência do par negativo. } \\
\text { " Prevalência do par positivo }\end{array}$} \\
\hline
\end{tabular}

Figura 19 - Comparativo entre os resultados do teste DS. Fonte: Elaborado pelas autoras, 2017.

\subsection{Revisão do projeto com base na avaliação dos usuários}

O resultado do teste de usabilidade mostrou que a forma de manusear o produto foi o ponto com mais avaliações negativas, então esse seria o principal ponto a ser repensado no design do abridor. A equipe concordou que o produto não é tão intuitivo em sua forma de uso, principalmente porque seu formato não remete a nenhuma característica do modelo convencional, o que confunde o usuário, uma vez que ele, automaticamente, tenta reproduzir o modo de uso ao qual ele está acostumado.

Portanto, como o formato em si do objeto não causou desconforto, acreditamos que uma solução possível para esse problema de intuitividade seria a construção de um suporte que induzisse o usuário a pegar o produto na posição correta. Assim, além de elucidar a forma de uso, o suporte também serviria para expor o objeto como parte da decoração da cozinha ou churrasqueira. As ideias iniciais sugerem que o suporte seja preso a uma parede, e o produto seja encaixado a ele, com a lâmina voltada para o chão. $16^{\circ}$ Ergodesign - Congresso Internacional de Ergonomia e Usabilidade de Interfaces Humano Tecnológica: Produto, Informações Ambientes Construídos e Transporte

$16^{\circ}$ USIHC - Congresso Internacional de Ergonomia e Usabilidade de Interfaces Humano Computador

CINAHPA | 2017 - Congresso Internacional de Ambientes Hipermídia para Aprendizagem.

\section{Conclusão}

Por fim, os resultados dos testes indicam que o protótipo final atendeu às diretrizes do projeto. $\mathrm{O}$ produto proposto obteve bons resultados relacionados tanto à sua estética quanto aos requisitos ergonômicos. A interdisciplinaridade proposta pelos docentes nos permitiu desenvolver todas as etapas de concepção do produto, nas quais foi possível perceber o quanto a experiência do usuário é importante. A aplicação de testes de usabilidade aumentou a compreensão das reais necessidades dos usuários e das formas de interação com interfaces, para dessa forma, tomar decisões mais assertivas durante o desenvolvimento do produto. Uma das limitações dos testes foi ter envolvido apenas jovens adultos, o que restringe os resultados ao apontamento das necessidades desse público e não reflete as dificuldades de outros grupos, como idosos por exemplo. No entanto, para o aprendizado o trabalho interdisciplinar obteve excelentes resultados, providenciando orientações para o progresso do projeto e beneficiando o grupo no aprendizado do desenvolvimento de design centrado no usuário.

\section{BIBLIOGRAFIA}

ASSOCIAÇÃO BRASILEIRA DE NORMAS TÉCNICAS. NBR 10098: Folha de desenho leiaute e dimensões. Rio de Janeiro: 1987.

NBR 10582: Apresentação da

folha para desenho técnico. Rio de Janeiro: 1988.

IIDA, ITIRO. Ergonomia : projeto e produção. / Itiro Iida - $2^{\mathrm{a}}$ edição ver. E ampl. - São Paulo:

Editora Blucher, 2005.

MEDOLA, F. O., PASCHOARELLI, L. C.

Resultados Teste de Usabilidade 1. Bauru, 2016.

NORMAN, DONALD A. O design do dia-a-dia./ Donald A. Norman; tradução Ana Deiró. - Rio de Janeiro: Rocco, 2006. 


\section{$16^{\circ}$ \\ ERGODESIGN USIHC CINAHPA}

$16^{\circ}$ Ergodesign - Congresso Internacional de Ergonomia e Usabilidade de Interfaces Humano Tecnológica: Produto, Informações Ambientes Construídos e Transporte

$16^{\circ}$ USIHC - Congresso Internacional de Ergonomia e Usabilidade de Interfaces Humano Computador

CINAHPA | 2017 - Congresso Internacional de Ambientes Hipermídia para Aprendizagem.

PASCHOARELLI, L. C. Usabilidade aplicada ao design ergonômico de transdutores de ultrassonografia: uma proposta metodológica para avaliação e análise do produto. 2003. 142 p. Tese (Doutorado) - UFSCar, São Carlos, 2003.

PASCHOARELLI, L. C.; CAMPOS, L. F. A.

Usabilidade e seus diferentes enfoques no design ergonômico. In: Ensaios em design: pesquisa e projetos. Bauru, SP: Canal 6, 2013. 